\title{
Using Online Texts to Build Independent Readers in ESL Classrooms
}

\author{
Kshema Jose ${ }^{1, *}$ \\ ${ }^{1}$ School of English Language Education, The English and Foreign Languages University, Hyderabad, India \\ *Correspondence: Dept of Training and Development, School of English Language Education, EFL University, \\ Hyderabad, India. E-mail: kshema@efluniversity.ac.in
}

Received: June 29, 2021

doi:10.5430/ijelt.v8n2p10
Accepted: July 11, $2021 \quad$ Online Published: July 19, 2021

URL: https://doi.org/10.5430/ijelt.v8n2p10

\begin{abstract}
Studies with proficient users of English suggest that readers demonstrate deeper comprehension of texts when reading non-linear hypertexts than when reading linear texts. This is attributed to the networked nature of texts that helps readers exercise cognitive flexibility. An aspect that remains largely unresearched is the potential of linear online texts to facilitate comprehension in readers who are non-proficient users of English.

Keeping in mind the fact that a majority of readers reading online texts in English can be hindered by three types of comprehension deficits - low levels of language proficiency, non-availability of prior knowledge, or both - this study investigated the interactive effects of two salient features of online texts, viz., non-linearity in the presentation of text and the availability of additional sources of information, on the reading comprehension of ESL readers. Two groups of readers with high and low levels of English proficiency read twelve texts on familiar and unfamiliar topics in print, linear online, and non-linear online modes. A comparison of readers' responses to comprehension questions and free recalls showed that those with low linguistic competence and/or topic familiarity were able to achieve better comprehension of linear online texts than print texts or non-linear online texts. The findings indicate that text linearity when combined with the presence of multiple information resources (both provided by the author within the text and freely available on the internet) might have the potential to scaffold linguistic and content knowledge deficits in ESL readers and promote deep levels of comprehension.
\end{abstract}

Keywords: hypertext literacy, online reading, ESL readers, cognitive flexibility, autonomous readers, digital divide

\section{Introduction}

Considering that a majority of texts read in the near future could be online, and a large part of which could be in English, it is important to investigate the online reading comprehension processes of ESL readers so that reading instruction in the ESL classroom becomes more informed and facilitates the development of information literacy skills relevant for the $21^{\text {st }}$ century student (Leu, Kinzer, Coiro, Castek \& Henry, 2017; Kanniainen, Kiili, Tolvanen, Aro \& Leppanen, 2019). The process of acquiring information from any text involves the interaction of reader factors like language proficiency, reading competence, levels of prior knowledge, strategies used, etc. with text variables such as text structure, text genre, organisation devices, etc. (Tompkins, 2014). This paper reports a study undertaken to explore the reading processes of ESL readers reading authentic online texts and attempts to identify reader and text factors that could influence the comprehension of these texts. The study investigated the interactive effects of reader factors such as linguistic, formal, and content schemata on ESL readers' comprehension of linear and non-linear online texts to determine features of online texts that can encourage text comprehension.

Three concepts form the theoretical underpinnings of this study: hypertext literacies, cognitive flexibility, and the construction-integration model of reading.

\subsection{Hypertext Literacies}

Literacy in the $21^{\text {st }}$ century is no longer restricted to print reading and writing (Hartman, Morsink \& Zheng, 2010). The traditional skills of literacy - the 3Rs of reading, writing and arithmetic, are now increasingly transacted through technology tools creating newer literacies like texting literacy, gaming literacy, visual literacy, mobile literacy, code literacy, and hypertext literacy (Dudeney, Hockly \& Pegrum, 2013) that complement the traditional notions of literacy. 
Of interest to this paper is hypertext literacy, i.e., one's ability to navigate hyperlinks to achieve successful comprehension of linked information (Dudeney \& Hockley, 2016).

Hypertexts are not new for the $21^{\text {st }}$ century digital reader. A hypertext is a collection of networked texts (or chunks of information called nodes) connected to each other through hyperlinks (the fragment of information that the reader clicks, also called the anchor). A writer of digital texts employs hyperlinks to provide the reader access to a variety and number of sources of information. This research investigates the usefulness of two types of hyperlinks commonly employed by hypertext writers - those that are used to connect the reader to different parts of the main text and those that provide content to support or assist comprehension of the main text. While visiting the former is integral for text comprehension, reading the contents of the latter may not be essential for text comprehension as they usually function as adjunct aids. Nodes of adjunct hyperlinks connect the reader to word meanings, background information, paraphrases, additional examples, illustrations, explanation in simpler language, further details, multimedia representations of information, sources for further reading, information on related topics, etc. to scaffold their process of information acquisition. Such link contents support the comprehension processes of readers who might be disadvantaged by language competency and/ or topic familiarity.

Miall (1997) categorises hypertexts into two - self-navigating hypertexts and pre-structured hypertexts. Self-navigating hypertexts present information as short separate sections, or nodes with no author-imposed reading order. Such texts provide readers a choice of hyperlinks to decide and design their reading order. Pre-structured texts, on the other hand, manifest a fixed or author-imposed reading order. They are presented as complete texts that are either scrollable or employ forward and backward buttons to allow readers to move linearly from one part of the text to the next. Pre-structured texts might also employ hyperlinked overviews or table of contents to make the reading route clear (Rouet \& Britt, 2014). Additionally, both self-navigating and pre-structured hypertexts employ adjunct hyperlinks to support readers' comprehension of texts. All these make navigating essential for successful comprehension of hypertexts (Blom, Segers, Knoors, Hermans \& Verhoeven, 2018).

However, navigation is not always an easy task. There are no rules that specify the amount or type of information a node should contain or as to what gets linked to what. The hyperlink/ anchor can be a word, phrase, sentence, image, or any piece of information that often gives no indication about its contents nor its relationship with the text or with the other nodes in the text. A good hypertext reader is constantly deciding which links to click by predicting link contents, determining the quality of information they contain, relating new information with what is already accessed, and synthesising information from multiple nodes. Successful comprehension thus depends on the reader's judgement of node contents, which in turn is determined by their reading comprehension ability, level of linguistic proficiency, and familiarity with the topic (Fitzsimmons, Weal \& Drieghe, 2019).

Reading of hypertexts is further compounded by the fact that online readers also browse web resources to aid their comprehension of text. Typically, such a reader identifies a need for additional information, uses search engines to explore and discover information, selects the type of information required, retrieves it, collects more information if required, and finally integrates these with information in the original text to construct a cohesive mental model of the text (Tierney, 2009). Researchers Spiro, Coulson, Feltovich \& Anderson (1988) argue that hypertext reading that entails navigation among multiple links and synthesising of information from several nodes can promote cognitive flexibility, an attribute that contributes to effective and deep learning of complex concepts.

\subsection{Cognitive Flexibility and Hypertext Reading}

Cognitive flexibility theory (Spiro, Coulson, Feltovich \& Anderson, 1988) argues that to achieve advanced or deep-level comprehension of texts, readers should be given opportunities to revisit the same material, several times, in rearranged contexts, and form different conceptual perspectives. Cognitive flexibility is the ability of the reader to visit bits of information, multiple times, in differing orders, and form connections among these disparate pieces of texts. Re-interpreting cognitive flexibility theory in the context of hypertexts, Spiro, et. al. (1988) explain that self-navigating hypertexts with their complex and ill-structured presentation of knowledge (termed ill-structured since these texts demonstrate knowledge interconnectedness and an absence of a hierarchical structure) are best for advanced knowledge acquisition since readers are engaged in frequent re-construction and restructuring of their knowledge by deploying higher-order reading skills like inference, analysis, and synthesis of information (Rouet \& Britt, 2014); resulting in acquisition of deep and meaningful learning, and retention of text information (Fitzsimmons, Weal \& Drieghe, 2016).

In the next section we look at the various reader variables and text factors that influence construction of mental models of text meaning. 


\subsection{Construction-integration Model of Reading Comprehension}

According to the construction-integration model of reading comprehension (Kintsch \& Welsch, 1991; Kintsch, 2004), text comprehension occurs when readers construct mental representations of text information by forming interrelationships among various information in the text and integrating them with relevant prior knowledge. Kintsch (1998) elaborates that text comprehension takes place at different levels. A mental representation is first constructed from the text's linguistic input. As more and more linguistic input is received, the mental model gets elaborated by the reader who forms connections among the information presented in the different sentences. Finally, the textual model is integrated with the reader's prior knowledge, by linking the new information with what is already stored in their memory.

According to this model, the reader's memory for text meaning is represented at three levels, viz., surface, textbase, and situation models. A surface representation of the words and sentences of the text in one's memory means the reader has achieved only very superficial comprehension or no comprehension at all. A textbase representation is created by synthesising various text propositions to form connections among different parts of the text and construct a global organisation of the text. Textbase information is later hierarchically organised and reconstructed by integrating it with the reader's existing knowledge, thus creating a situation model of the text. Inability to build a situation model of the text means shallow comprehension has taken place.

Both construction and integration of text information are facilitated by the interaction of various reader variables and text factors. Of special significance to this paper is the working of the reader variable background knowledge that includes content schema (knowledge of the topic), linguistic schema (reader's level of language proficiency) and formal/textual schema (knowledge of the text structure). While content schema helps to understand incoming information by connecting it with the relevant topic-related knowledge that is already available in the reader, linguistic schema, determined by one's level of language proficiency, provides the necessary language support. Formal schema guides the information acquisition process by helping the reader recognise text types, utilise text structures, identify metatext markers employed, etc. It is a logical conclusion then that factors like familiarity of topics (high levels of content schema), good levels of language proficiency (high linguistic schema), and awareness of and ability to use text structures (high formal schema) can raise the levels of text comprehension achieved by a reader. Conversely, an absence of any one of these schemata can be detrimental to successful comprehension of texts.

\section{Review of Relevant Studies}

Appearance of the text as a network of interconnected segments, absence of linearity, and the consequent lack of signaling devices in self-navigating hypertexts can make the process of reading hypertexts cognitively demanding due to the absence in the reader of a formal schemata that matches the fragmented or ill-structured nature of texts. Cognitive flexibility theory argues otherwise, the intense reader-text interaction, a result of hypertext reading can act as a facilitator of deep level comprehension. In this section we look at research conducted in the area of reading self-navigating or non-linear online texts.

Several researchers have reported that reading self-navigating hypertexts disrupts readers' comprehension processes by causing cognitive overload (Niederhauser, Reynolds, Salmen \& Skolmoski, 2000; Kester \& Kirschner, 2009; Scharinger, Kammerer \& Gerjets, 2015) and navigation disorientation (Sung, Wu, Chen \& Chang, 2015), both resulting in negative reading outcomes.

Examining reader factors like levels of prior knowledge, levels of linguistic competence, and reading ability, researchers like Tierney (2009); Amadieu \& Salmerón (2014); Fesel, Segers \& Verhoeven (2017); and Segers (2017) found that readers with good prior knowledge demonstrated greater interaction with the text while reading an incoherent text as they resorted to inferencing to establish connections among disparate text segments, resulting in deep-level text comprehension. Such readers were able to construct better textbase and situation levels of comprehension while reading self-navigating hypertexts, whereas cognitive resources of readers with low prior knowledge were employed in making sense of the unfamiliar topic, deciding which links to click, comprehending large amounts of scattered text segments, and establishing cohesion among networked texts. These activities consumed precious cognitive resources resulting in less cognitive space available for inferencing and construction of a situation model of the text (Carr, 2010). Readers with low prior knowledge were seen to construct better situation models from highly coherent and structured texts than from self-navigating ones. 
It has also been reported that while reading self-navigating hypertexts, readers with low levels of language competence such as low levels of vocabulary in addition to low prior knowledge complained of cognitive overload that caused navigation disorientation (DeStefano \& LeFevre, 2007) leading to shallow comprehension (Wolf, Ullman-Shade \& Gottwald, 2012; Blom, et. al., 2018).

A third factor researched is the reading ability of participants. Research by Passig \& Nadler (2010), Naumann \& Salmerón (2016), and Amadieu, Lemarié \& Tricot (2017) demonstrated that navigating hyperlinks led to exploration, discovery, integration of information, and high metacognitive activity only in readers with good offline/ print reading ability or good vocabulary repertoire. Naumann \& Salmerón (2016) and Fitzsimmons, Weal \& Drieghe (2019) concluded that evaluating the purpose of hyperlinks, predicting their contents, and navigating a reading path required high-level text processing abilities and that only readers with high prior knowledge, threshold levels of print or offline reading ability, and hypertext reading expertise seemed to be capable of comprehending networked texts.

Research until now have established the interactive effects of language proficiency, reading competence, online reading expertise, and topic knowledge on readers' comprehension of self-navigating hypertexts. Researchers concur that it is only readers with high levels topic, and linguistic schemata and good reading abilities who can deploy higher order reading skills like inferencing and synthesis and demonstrate cognitive flexibility while reading self-navigating hypertexts.

In the classroom where this researcher was the teacher, it was repeatedly observed that readers with low linguistic proficiency, regardless of familiarity of topics read, demonstrated better comprehension of pre-structured hypertexts than linear, paper-based texts. What was remarkable was that these readers were also able to answer global and inferential questions while reading linear online texts, abilities not demonstrated during their reading of print texts. This was the genesis of this study.

\section{Method}

The question this researcher set out to investigate was whether the affordances of pre-structured online texts, viz., use of hyperlinks to scaffold reading through the use of adjunct aids and access to digital resources on the internet could facilitate text comprehension of readers with low levels of topic and/or linguistic schemata. As far as this researcher is aware, research until now have not investigated how readers interact with authentic texts on the internet. Consequently, no attempt has been made to study the effects of free browsing of the internet for additional online resources on the comprehension of readers. This researcher was curious to examine if the act of navigating through and forming connections among multiple resources (adjunct aids within the text and resources on the internet) while reading a linear online text could facilitate cognitive flexibility and promote comprehension of texts in readers disadvantaged by linguistic and/or content schemata.

\subsection{Research Design}

To explore the effect of linguistic competence, two groups of ESL students were chosen for the study - one group with high levels of competence in English (referred to as HL2 in this paper) and another with low levels of English language proficiency (termed LL2). Effect of prior knowledge was studied by choosing topics that were familiar (referred to as high prior knowledge or HPK in this paper) and topics that were unfamiliar to the students (mentioned as low prior knowledge or LPK). To investigate the effect of text linearity and availability of comprehension resources, two types of hypertexts were chosen - pre-structured (referred to as PS) and self-navigating hypertexts (SN), in addition to print texts (PR). All students read three types of texts, viz., print; linear or pre-structured online; and non-linear or self-navigating online texts on familiar and unfamiliar topics.

\subsection{Research Questions}

To articulate the interactivity between reader factors (linguistic proficiency in L2 and content schemata) and text factors (text linearity and presence of additional comprehension resources) in ESL users reading authentic hypertexts, two large questions were formed to guide the study:

1. Can non-linearity of texts facilitate comprehension in ESL readers reading online texts?

2. Can the presence of additional resources help ESL readers overcome deficits in their linguistic and/or content schemata while reading online texts?

\subsection{Participants of the Study}

In the university where the study took place, students pursuing undergraduate programmes in foreign languages are 
offered a four-month elective course called "General English language proficiency" from semesters 1 to 4 . The "General English language proficiency" in semester 3 is a course in Academic Reading that focuses on developing reading comprehension skills through print texts. In 2018, the course was updated to include hypertext literacy. Reading of electronic texts was introduced as a ten-hour component and in 2019 it was extended to a 24-hour module. The writer was the teacher of the Academic Reading course during both times.

92 students registered for Academic Reading in 2019. Using purposive sampling, 68 students were selected based on their levels of English language proficiency. The grades they received for the "General English language proficiency" paper in their preceding semester, i.e., semester 2, were used to determine students' level of English language proficiency. Accordingly, 32 high proficiency students (described as high L2 or HL2 in this paper) who received grades $\mathrm{A}+$ and $\mathrm{A}$ (as per the standardised university grading procedure, the corresponding marks range from 87 to 72 out of a total of 100); and 36 students with low intermediate proficiency (described as low L2 or LL2) with grades $\mathrm{C}$ and $\mathrm{D}$ (ranging from 48 to 37 marks) were selected for the study. Of the 68 students selected, 41 were girls and 27 were boys, all within the age group $19-21$. Informed consent was obtained from all the students to use data collected from them for research purposes.

All 92 students, except one who had a physical disability, reported more than five years' familiarity with the use of the internet and technology tools. The student who had an orthopaedic handicap reported around three years' familiarity with digital technology. All students spent $4-5$ hours on the internet daily and hence were treated as expert users of the internet.

Topic familiarity was determined through self-rating of prior knowledge. At the start of the course, all students were given a list of 30 topics and were asked to mark their level of familiarity with each topic on a 4-point rating Likert scale. Based on the mean scores, eight familiar topics and ten unfamiliar topics were identified to choose reading texts for the course.

\subsection{Materials and Instruments}

A total of twelve reading texts in three modes were used during the study. In the first three months of the course, all students read only print texts (PR). During the last month of the course, students were given eight online texts for reading - four pre-structured or linear hypertexts (PS) and four self-navigating or non-linear hypertexts (SN). Of these, two PS and two SN texts were on topics familiar to the students (identified as HPK or high prior knowledge in this paper) and the other two in both modes were on unfamiliar topics (LPK or low prior knowledge). All the texts showed a mean reading difficulty of 11.4 on the Flesch-Kincaid grade level readability index. Each reading text was followed by local, global, and inferential comprehension questions that carried a total of ten marks. Content validity of comprehension questions was established if the researcher and another teacher (with 15 years' experience in ESL teaching) marked an item as 'essential.' The study also employed free recalls as a tool to measure students' levels of comprehension. For free recall, the only instruction given was, 'tell me everything that you remember from the text'. Additional sources of data were a daily $\log$ maintained by the researcher and semi-structured student interviews.

\subsection{Data Collection Procedure}

All students read two pre-structured texts on familiar topics followed by two pre-structured texts on unfamiliar topics. After this, they read two self-navigating texts on familiar topics and finally two self-navigating texts on unfamiliar topics. After reading each text, students were asked to respond to comprehension questions. They were allowed to consult the text (website) while answering questions. Students were then administered a distractor task following which they were asked to audio record a free recall of the text.

\subsection{Data Analysis}

This study employed a mixed method design to answer key research questions. Students' responses to the comprehension items that accompanied the four pre-structured and four self-navigating hypertexts were scored by the researcher. Comprehension scores received for the four print texts (two on familiar topics and two on unfamiliar topics) read in the penultimate month of the course were also calculated. Quantitative analysis of reading comprehension scores was performed using ANOVA to determine if there were statistically significant differences between the means of scores in the three text types - print texts, pre-structured hypertexts, and self-navigating hypertexts.

Findings were analysed to test the following hypotheses: 
1. There is a statistically significant difference in reading comprehension between PR, PS and SN modes of HL2 reading familiar texts.

2. There is a statistically significant difference in reading comprehension between PR, PS and SN modes of HL2 reading unfamiliar texts.

3. There is a statistically significant difference in reading comprehension between PR, PS and SN modes of LL2 reading familiar texts.

4. There is a statistically significant difference in reading comprehension between PR, PS and SN modes of LL2 reading unfamiliar texts.

A random sample of size $n=12$ was chosen from low L2 students for semi-structured interviews. Free recalls of these students were analysed qualitatively before the interviews. Observations derived from analyses of free recalls and inputs from researcher log were used to guide student interviews. The free recalls were transcribed, and their content coded for the presence of main ideas and supporting details of the text, and to detect recall of wrong or irrelevant information, if any. The language of free recalls was examined to determine if they were mere repetitions (indicative of surface level comprehension) or paraphrases (construction of textbase model) of text content or if there were attempts to link text information with prior knowledge (generation of situation model). Ten free recall transcripts were coded separately by the researcher and a second researcher working in the area of English language education. Intercoder agreement was calculated at 94 percent. The rest of the free recalls were coded by the researcher alone.

Semi-structured interviews were also examined to identify student perceptions regarding reading print, pre-structured and self-navigating texts.

\section{Findings}

Data was analysed and interpreted to examine how two reader variables, viz., prior knowledge and level of L2 proficiency, interacted with the two text variables - lack of linearity and presence of additional information, to effect comprehension of online texts in these readers.

\subsection{Hypertext Reading Performance of ESL Learners with High Levels of L2 Proficiency (HL2)}

A one-way analysis of variance (ANOVA) was performed to evaluate the impact of the three text types (print texts (PR); linear or pre-structured online texts (PS); and non-linear online or self-navigating texts (SN) on the reading comprehension performance of HL2 readers.

Table 1. ANOVA Values of Readers with high L2 Level Reading Familiar and Unfamiliar Topics on Print, Pre-structured and Self-navigating Modes

\begin{tabular}{lllll}
\hline & $\mathrm{PR}$ & $\mathrm{PS}$ & $\mathrm{SN}$ & ANOVA \\
\hline HL2 HPK (familiar topics) & $\mathrm{M}=15$ & $\mathrm{M}=14.4$ & $\mathrm{M}=16.5$ & F-statistic value $=8.21171$ \\
& $\mathrm{SD}=1.7$ & $\mathrm{SD}=1.6$ & $\mathrm{SD}=1.4$ & P-value $=0.00047$ \\
HL2 LPK (unfamiliar & $\mathrm{M}=10.3$ & $\mathrm{M}=13$ & $\mathrm{M}=7$ & F-statistic value $=90.91451$ \\
topics) & $\mathrm{SD}=1.9$ & $\mathrm{SD}=1.6$ & $\mathrm{SD}=2$ & P-value $=0$ \\
\hline
\end{tabular}

Results indicate that HL2 readers performed better in $\mathrm{SN}(\mathrm{M}=16, \mathrm{SD}=1.9)$ than in PR $(\mathrm{M}=15, \mathrm{SD}=1.7)$ and PS $(\mathrm{M}=14.4, \mathrm{SD}=1.6)$. ANOVA scores of these readers reading familiar topics show that there are significant group differences in the scores of reading comprehension questions in the three text types, $\mathrm{F}=8.21171, \mathrm{P}$ value $=0.00047$. Tukey's test indicates that the score of SN is significantly higher than PR, $p=.004$ and PS, $p=.002$. However, there are no significant differences between PS and PR, $p=.214$.

HL2 readers reading unfamiliar topics comprehended better in the PS $(M=13, S D=1.6)$ than in $P R(M=10.3$, $\mathrm{SD}=1.9$ ) mode. It is to be noted that HL2 readers reading unfamiliar topics demonstrated least comprehension in $\mathrm{SN}(\mathrm{M}=7, \mathrm{SD}=2)$. ANOVA results indicate that there are significant group differences in the scores of reading comprehension questions in the three text types, $\mathrm{F}=90.91451$, P-value $=0$. Tukey post hoc test indicates that the score of PS is significantly higher than $\mathrm{SN}, p=.002$. The score of PR is also significantly higher than SN, $p=.002$. However, there are no significant differences between PS and PR, $p=.156$. 
Results indicate that HL2 readers while reading texts on familiar topics gained highest levels of comprehension while reading self-navigating hypertexts, whereas pre-structured hypertexts helped these readers attain good levels of comprehension of unfamiliar topics. Confirming findings from previous research that high linguistic and topic competence are pre-requisites for comprehension of self-navigating hypertexts, this study also concludes that readers with high levels of L2 proficiency gained deep level comprehension of texts on familiar topics while reading self-navigating texts. This was followed by pre-structured texts and finally print texts. Comprehension of unfamiliar topics, on the other hand, was facilitated by pre-structured, print, and self-navigating texts in that order. These findings point towards the possible role played by text coherence and online resources in promoting deep reading comprehension in HL2 readers hindered by lack of topic familiarity.

\subsection{Hypertext Reading Performance of ESL Learners with Low Levels of L2 Proficiency (LL2)}

Results of ANOVA performed to evaluate the impact of the three text types (print texts (PR); linear or pre-structured online texts (PS); and non-linear online or self-navigating texts (SN) on the reading comprehension performance scores of LL2 readers are given in table 2.

Table 2. ANOVA Scores of Readers with Low L2 Level Reading Familiar and Unfamiliar Topics on Print, pre-structured and Self-navigating Modes

\begin{tabular}{lllll}
\hline & PR & PS & SN & ANOVA \\
\hline LL2 HPK (familiar topics) & $\mathrm{M}=6.3$ & $\mathrm{M}=9.2$ & $\mathrm{M}=4.4$ & F-statistic value = 19.63047 \\
& $\mathrm{SD}=2.5$ & $\mathrm{SD}=1.7$ & $\mathrm{SD}=2.6$ & P-value $=0$ \\
& & & \\
LL2 LPK (familiar topics) & $\mathrm{M}=2.4$ & $\mathrm{M}=6$ & $\mathrm{M}=1.5$ & F-statistic value $=44.688$ \\
& $\mathrm{SD}=1.2$ & $\mathrm{SD}=2$ & $\mathrm{SD}=1$ & $\mathrm{P}$-value $=0$ \\
\hline
\end{tabular}

LL2 readers reading texts on familiar topics showed highest performance scores in PS (M=9.2, $\mathrm{SD}=1.7)$ than in $\mathrm{SN}$ $(\mathrm{M}=4.4, \mathrm{SD}=2.6)$ and $\mathrm{PR}(\mathrm{M}=6.3, \mathrm{SD}=2.5)$. ANOVA results report significant group differences in the scores of reading comprehension questions in the three text types, $\mathrm{F}=19.63047, \mathrm{P}$-value $=0$. Tukey's test indicates that the score of PS is significantly higher than $\mathrm{SN}, p=.02$. The score of PS is also significantly higher than PR, $p=.005$ and the score of PR is significantly higher than $\mathrm{SN}, p=.045$

While reading texts on unfamiliar topics, LL2 readers showed highest comprehension scores on PS $(\mathrm{M}=6, \mathrm{SD}=2)$ than $\mathrm{SN}(\mathrm{M}=1.5, \mathrm{SD}=1)$ and $\mathrm{PR}(\mathrm{M}=2.4, \mathrm{SD}=1.2)$. ANOVA results report significant group differences in the scores of reading comprehension questions in the three text types, $\mathrm{F}=44.688$, P-value $=0$. Tukey's test indicates that the score of PS is significantly higher than $\mathrm{SN}, p=.002$. The score of PS is also significantly higher than PR, $p=.008$. However, there are no significant differences between PR and $\mathrm{SN}, p=.273$

Results show that ESL readers with low levels of L2 proficiency found pre-structured hypertexts easiest for comprehending texts on both familiar and unfamiliar topics.

\section{Discussion}

A significant potential of online texts suggested by the findings of this study is that both HL2 as well as LL2 readers were able to overcome deficits in their linguistic and/ or content schemata and demonstrate high levels of comprehension when reading was supported by a linear text structure and availability of comprehension aids as in the case of PS texts.

Analyses of free recalls produced by the 12 LL2 readers showed that the highest occurrence of situation clauses and the least number of surface clauses for both familiar and unfamiliar texts were evident in recalls produced after reading pre-structured online texts. Free recalls of PS texts of these readers also displayed more instances of accurate recall of main ideas and supporting details than their free recalls of PR or SN texts. LL2 readers while reading PS texts demonstrated abilities to paraphrase meanings of unfamiliar words and phrases; form relations among different parts of the text; make inferences; recall and/or gather prior knowledge relevant for text comprehension; and connect text information with information collected from external sources. Compared to the free recalls of PS texts, those of SN and PR texts were on several occasions incomplete, and were composed of disjointed sentences, carried inaccurate information, and consisted of phrases and text chunks memorised from the original text. These observations potentially endorse the findings from the quantitative analysis of reading comprehension scores 
presented in the previous section.

During interviews, a few LL2 readers reported that encountering links in the PS texts made them ask themselves questions regarding the content of links and the need to visit a link. Such questions also helped them identify gaps in their comprehension; realise the need for additional sources of information; search for new information; and form connections among information from multiple links. Described by one of the students as "a full-time chatting with text," this interaction, engagement, and heightened metacognition seemed to have contributed not only to a more accurate comprehension of PS texts but also performance of inferencing and synthesising - cognitive abilities indicative of cognitive flexibility.

Two benefits of reading linear online texts as listed by LL2 readers were the availability of online dictionaries to understand word meanings and the easy access to online resources that provided alternate, simpler, detailed, multimodal, and multiple contexts that made comprehending the original text content easier. As a reader reported, "it's not like reading one text again and again even when you don't get it...here you're Googling and reading different kinds of texts all about the same topic."

Despite the availability of online resources, the absence of a linear text structure made comprehending self-navigating texts a highly resource-consuming task since readers were required to compensate for deficits in their formal, linguistic, and content schemata by utilising their cognitive resources to establish a reading order through the various segments of the original text; to synthesise information from multiple external sources visited; and to connect the latter with the former. One reader described SN texts as "twisted mazes." Another reader explained, "there are many many texts and you're doing many many things ... You get one idea and then you can't remember because you're doing many things together..."

To summarise, the absence of formal schemata while reading SN online texts seems to promote higher levels of comprehension only in readers who have high levels of linguistic and topic schemata. For readers who lack topic and/ or linguistic schemata, pre-structured online texts that conform to the conventions of text linearity and give readers access to additional resources seem to best facilitate deep levels of reading comprehension.

\section{Limitations of the Study}

The limitations are primarily because the study took place within the constraints of a classroom-based course where the researcher was the instructor. Since the participants of the study formed a part of the whole class, selection of texts based on accurate determination of levels of prior knowledge was not a viable option. For the same reason, it was also not possible to use retrospective or introspective methods of data collection though the researcher is aware that such methods would have provided access to more insightful data. A second limitation is that, since groups were chosen based on their similarity in sizes, readers with extremely low levels of L2 proficiency were not studied. Further empirical, classroom-based studies are required to substantiate the claims made in this paper.

\section{Implications of the Study}

The findings of this study seem to imply that hypertext reading expertise and familiarity with the use of the internet might help readers overcome prior knowledge deficits, lack of linguistic competence, and low print reading abilities. By indicating the possible advantages of pre-structured online texts over print texts in promoting reading comprehension and facilitating the development of higher-order reading skills in LL2 ESL readers, this study recommends that hypertext literacy be made a part of ESL reading classrooms.

Using pre-structured hypertexts in reading classes could also help build autonomous reading habits in ESL readers. Perfetti \& Stafura (2014) warn us that topic knowledge and vocabulary are both important but not sufficient determiners of successful L2 comprehension; explicit teaching of word meanings and delivering background information in classrooms do not guarantee development of lifelong learning. Instead, students should be taught to build their own vocabulary, and discover and use requisite background knowledge in their reading. To develop such lifelong learning habits, Oakhill (2019) recommends that readers be given only rudiments and encouraged to not only understand word meaning, but also infer what that word means in a context and build a network of associated meaning around the word using the context. In this study, it was observed that several readers while reading pre-structured online texts did precisely this - they interacted with link contents, consulted additional online resources to understand word meanings, checked for the use of the word in sentences and longer texts, viewed related images, referred dictionaries for antonyms, searched for the use of the word in other contexts, and built elaborate content knowledge, 
thereby acquiring depth of vocabulary (Oakhill, 2019). LL2 readers in this study reported that they understood the meanings of words and phrases such as 'parafoveal vision', 'janitor', 'talking head', 'perceptual span' etc. due to the "extra sites" they visited.

The research reported here also points out the need to examine closely the differences between how we read on the internet and how we read print texts. It is time to revisit the question, "Hypertext Reception: Do we need to rethink our reading models?" (Jose, 2004). While reading in online reading environments, it was observed that reader factors traditionally termed internal factors (in this study, topic knowledge and linguistic competence) ceased to be strictly internal. In online reading environments, the reader and the internet became one, blurring the line between internal reader factors and external text factors. The immediacy with which we are able to retrieve information from the internet reduces the gap between the readers' schemata and digital resources on the internet. A large majority of today's readers consider internet resources a part of their own cognitive resources. The internet has become a Source of external memory or an extension of our brains (Wegner \& Ward, 2013a; Barr, Pennycook, Stolz \& Fugelsang, 2015). In this study, it was observed that reader brains were no longer the sole seats of prior knowledge that helped with the comprehension of texts; what was stored within the reader and what was available on the internet functioned together to help build accurate mental representations of texts in the participants of this study.

The brain-computer interface, or the splitting of our cognitive resources between the internet and human brain, also called the "inter-mind" by Wegner \& Ward (2013b) is a new form of enhanced intelligence that Elon Musk (a technology entrepreneur) believes can help with cognitive enhancement (Marsh, 2018). Further research in hypertext comprehension can help us understand how the brain-computer interface can multitask to increase our cognitive capacities and facilitate better comprehension compared to the human mind working alone (Firth et. al., 2019). This could necessitate a re-interpretation of the models of reading comprehension that we are familiar with (Unrau, Alvermann \& Sailors, 2019).

\section{Suggestions for Further Research}

A question that merits investigation is how some low L2 readers were able to answer global and inferential questions while reading PS texts, an ability that was not manifested in their reading of PR or SN texts. One possibility is that these readers, all of them expert users of the internet, could have developed their reading abilities while reading online texts and not through print texts. However, a problem with this premise is that it is difficult to explain why these readers were unable to transfer their inferencing and synthesising abilities from online to print reading contexts. As pointed out by Spiro, et. al. (1988), it could be the nature of print texts - linear, well-structured, non-segmented that prevents readers' exercise of cognitive flexibility. Detailed empirical research needs to be undertaken to investigate the claim that the presence of hyperlinks and access to additional digital resources while reading linear online texts (both of which necessitate the cognitive act of forming connections among multiple link contents) can nurture cognitive flexibility in ESL readers.

Another probability is that these LL2 readers could have transferred their higher order reading skills in L1 to reading in L2 while reading PS hypertexts. Most ESL readers develop expertise or competence in reading in L1 before they start reading in English. The short-circuit hypothesis (Clarke, 1979) introduces the notion of a threshold of language proficiency that proposes that the L2 reader must reach a threshold level of L2 proficiency in order to transfer their reading ability from L1 to L2. Insufficient L2 proficiency short-circuits or restricts the transfer of L1 reading abilities to L2 reading (Taillefer, 1996). While reading PS texts, the availability of digital resources could have helped LL2 readers overcome their linguistic and content schemata deficits and achieve a threshold level of L2 where transfer of reading abilities from $\mathrm{L} 1$ was enabled. This paper thus raises the possibility that the level of L2 competence may not be a significant determiner of L2 reading comprehension levels while reading pre-structured hypertexts, since low L2 readers who have good reading abilities in L1 might be able to acquire a threshold level of L2 by utilising online language and content resources. Further research can help us determine if PS texts that provide access to vocabulary and content resources can help LL2 readers reach threshold levels of L2 linguistic competence which in turn can facilitate transfer and deployment of their L1 reading skills to L2 reading contexts.

\section{Conclusion}

By throwing light on the possibility that reading pre-structured online texts could promote cognitive flexibility and deep-reading comprehension in ESL readers with low L2 proficiency and/or low content knowledge, this research makes a case for explicit teaching and active promotion of hypertext literacy in ESL reading classes. Hypertext literacy 
is as much or even more significant than print literacy now. One of the eight aspects of digital divide listed by Wilson (2004), cognitive access to digital texts can be addressed by developing hypertext literacy in the ESL classroom. Building students' capacity to use the internet means they do not lose out on opportunities for professional and personal development (Lords Select Committee publications, 2017). And more importantly, developing readers who use digital content can help build readers who create digital content. Ensuring access to and encouraging creation of digital texts can bring more people from the periphery to the center thus reducing exclusion and inequality in the ownership of digital content (Wilson, 2012).

\section{References}

Amadieu, F., Lemarié, J., \& Tricot, A. (2017). How may multimedia and hypertext documents support deep processing for learning? Psychologie Française, 62(3), 209-221. https://doi.org/10.1016/j.psfr.2015.04.002

Amadieu, F., \& Salmerón, L. (2014). Concept maps for comprehension and navigation of hypertexts. In D. Ifenthaler \& R. Hanewald (Eds.), Digital knowledge maps in education. Technology-enhanced support for teachers and learners (pp. 41-59). New York: Springer.

Barr, N., Pennycook, G., Stolz, J. A., \& Fugelsang, J. A. (2015). The brain in your pocket: Evidence that Smartphones are used to supplant thinking. Computers in Human Behavior, 48, 473-480. ttps://doi.org/10.1016/j.chb.2015.02.029

Blom, H., Segers, E., Knoors, H., Hermans, D., \& Verhoeven, L. (2018). Comprehension and navigation of networked hypertexts. Journal of Computer Assisted Learning, 34(3), 306-314. https://doi.org/10.1111/jcal.12243

Carr, N. G. (2010). The Shallows: What the Internet is doing to our brains. New York: W. W. Norton.

Clarke, M. A. (1979). Reading in Spanish and English: Evidence from adult ESL students. Language Learning, 29, 121-150.

DeStefano, D., \& LeFevre, J. (2007). Cognitive load in hypertext reading: a review. Computers in Human Behavior, 23, 1616-1641.

Dudeney, G., Hockly, N., \& Pegrum, M. (2013). Digital literacies. Harlow, UK: Pearson.

Dudeney, G., \& Hockley N. (2016). Literacies, Technology and Language Teaching. In F. Farr \& L. Murray (Eds.), The Routledge handbook of language learning and technology (pp. 115-126). New York: Routledge.

Fesel, S. S., Segers, E., \& Verhoeven, L. (2017). Individual variation in children's reading comprehension across digital text types. Journal of Research in Reading, 41, 106-121. https://doi.org/10.1111/1467-9817.12098

Firth, J., Torous, J., Stubbs, B., Firth, J. A., Steiner, G. Z., Smith, L., Alvarez-Jimenez, M., Gleeson, J., Vancampfort, D., Armitage, C. J., \& Sarris, J. (2019). The "online brain": how the Internet may be changing our cognition. World Psychiatry, 18(2), 119-129. https://doi.org/10.1002/wps.20617

Fitzsimmons, G., Weal, M. J., \& Drieghe, D. (2016). Reading, processing and interacting with hypertext on the web. Proceedings of the 30th International BCS Human Computer Interaction Conference: Fusion! BCS Learning and Development Ltd.

Fitzsimmons, G., Weal, M. J., \& Drieghe, D. (2019). The impact of hyperlinks on reading text. PLoS ONE, 14(2). https://doi.org/10.1371/journal.pone.0210900

Hartman, D. K., Morsink, P. M., \& Zheng, J. (2010). From print to pixels: The evolution of cognitive conceptions of reading comprehension. In E. A. Baker (Ed.), The new literacies: Multiple perspectives on research and practice (pp. 131-164). New York: Guilford.

Jose, K. (2004). Hypertext Reception: Do we need to rethink our reading models? JEFL, 33, 31-38.

Kanniainen, L., Kiili, C., Tolvanen, A., Aro, M., \& Leppänen, P. H. T. (2019). Literacy skills and online research and comprehension: struggling readers face difficulties online. Reading and Writing, 32(9), 2201-2222. https://doi.org/10.1007/s11145-019-09944-9

Kester, Liesbeth \& Kirschner, Paul A. (2009). Effects of fading support on hypertext navigation and performance in student-centered e-learning environments. Interactive Learning Environments, 17(2), 165-179. https://doi.org/10.1080/10494820802054992 
Kintsch, W. (1998). Comprehension: A paradigm for cognition. Cambridge University Press.

Kintsch, W. (2004). The Construction-Integration Model of text comprehension and its implications for instruction. In R.B. Ruddell \& N.J. Unrau (Eds.), Theoretical models and processes of reading (pp. 1270-1328). Newark, DE: International Reading Association.

Kintsch, W., \& Welsch, D. (1991). The construction-integration model: A framework for studying memory for text. In W.E. Hockley \& S. Lewandowsky (Eds.), Relating theory and data: Essays on human memory in honor of Bennet B. Murdock (pp 367-385). Hillsdale, NJ: Lawrence Erlbaum.

Leu, D.J., Kinzer, C.K., Coiro, J., Castek, J., \& Henry, L.A. (2017). New literacies: A dual-level theory of the changing nature of literacy, instruction, and assessment. Journal of Education, 197(2), 1-18.

Lords Select Committee publications 2016-17. Communications and Digital Committee Publications. (2017). Growing up with the internet. HL Paper 130. UK Parliament publications. Retrieved on October 22, 2019 from https://publications.parliament.uk/pa/ld201617/ldselect/ldcomuni/130/13003.htm

Marsh, S. (2018). Neurotechnology, Elon Musk and the goal of human enhancement. Retrieved on August 2019 from

https://www.theguardian.com/technology/2018/jan/01/elon-musk-neurotechnology-human-enhancement-brain-co mputer-interfaces

Miall, D.S. (1997). Reading and writing hypertext. Retrieved on January 2020 from http://www.ualberta.ca/ dmiall/hypread.htm

Naumann, J., \& Salmerón, L. (2016). Does navigation always predict performance? Effects of navigation on digital reading are moderated by comprehension skills. The International Review of Research in Open and Distributed Learning, 17(1). https://doi.org/10.19173/irrodl.v17i1.2113

Niederhauser, D. S., Reynolds, R. E., Salmen, D. J., \& Skolmoski, P. (2000). The influence of cognitive load on learning from hypertext. Journal of Educational Computing Research, 23, 237-255. https://doi.org/10.2190/81BG-RPDJ-9FA0-Q7PA

Taillefer, G. (1996). L2 reading ability: Further insight into the short-circuit hypothesis. The Modern Language Journal, 80(4), 461-477. https://doi.org/10.2307/329726

Unrau, N. J., Alvermann, D. E., \& Sailors, M. (2019). Literacies and their investigation through theories and models. In D.E. Alvermann, N. J. Unrau, M. Sailors \& R.B. Ruddell (Eds.), Theoretical models and processes of literacy (pp 3-34). New York: Routledge.

Oakhill, J. (2019). TES podcast May 8, 2019. Retrieved on February 9, 2020 from https://www.tes.com/news/inference-why-comprehension-not-just-about-vocabulary-and-knowledge

Passig, D., \& Nadler, L. (2010). Structural and conceptual user interfaces and their impact on learning. Education and Information Technologies, 15, 51-66. https://doi.org/10.1007/s10639-009-9096-x

Perfetti, C., \& Stafura, J. (2014). Word knowledge in a theory of reading comprehension. Scientific Studies of Reading, 18, 22-37. https://doi.org/10.1080/10888438.2013.827687.

Rouet, J., \& Britt, A. (2014). Multimedia learning from multiple documents. In R. Mayer (Ed.), The Cambridge handbook of multimedia learning (pp 813-841). Cambridge: Cambridge University Press.

Scharinger, C., Kammerer, Y., \& Gerjets, P. (2015). Pupil dilation and EEG alpha frequency band power reveal load on executive functions for link-selection processes during text reading. PLoS ONE, 10(6). https://doi.org/10.1371/journal.pone.0130608

Segers, E. (2017). Children's hypertext comprehension. In E. Segers \& P. W. van den Broek (Eds.), Developmental perspectives in written language and literacy (pp 149-164). Amsterdam: John Benjamins. Retrieved on 6 May, 2020 from https://www.researchgate.net/publication/327973979_Children's_hypertext_comprehension

Spiro, R. J., Coulson, R. L., Feltovich, P. J., \& Anderson, D. K. (1988). Cognitive flexibility theory: Advanced knowledge acquisition in ill-structured domains. (Tech. Rep. No. 441). Urbana-Champaign, IL: University of Illinois, Center for the Study of Reading. Retrieved on 11 March, 2019 from https://www.ideals.illinois.edu/bitstream/handle/2142/18011/ctrstreadtechrepv01988i00441_opt.pdf?sequence=1 
Sung, Y. T., Wu, M. D., Chen, C. K., \& Chang, K. E. (2015). Examining the online reading behavior and performance of fifth-graders: evidence from eye-movement data. Frontiers in Psychology, 6(665). https://doi.org/10.3389/fpsyg.2015.00665

Tierney, R. J. (2009). Agency and artistry of meaning makers within and across digital spaces. In Susan Israel \& G. Duffy (Eds.), Handbook of research on reading comprehension (pp. 261-288). Erlbaum Associates/Routledge. $\begin{array}{lllll}\text { Retrieved on } & 1 & \text { March, } & 2020 & \text { from }\end{array}$ https://www.academia.edu/9755441/Tierney_R.J._2009_Agency_and_artistry_of_meaning_makers_within_and_ across_digital_spaces._In_Susan_Israel_and_G._Duffy_Eds._Handbook_of_Research_on_Reading_Comprehens ion_pp._261-288_Erlbaum_Associates_Routledge

Tompkins, Gail, E. (2014). Literacy for the 21st century: A balanced approach. Boston: Pearson.

Wegner, D. M., \& Ward, A. F. (2013a). The internet has become the external hard drive for our memories. Retrieved $\begin{array}{lllll}\text { on } & \text { February 27, from }\end{array}$ https:/www.scientificamerican.com/article/the-internet-has-become-the-external-hard-drive-for-our-memories/

Wegner, D. M., \& Ward, A. F. (2013b). How Google is changing your brain. Scientific American, 309(6), 58-61. https://doi.org/10.1038/scientificamerican1213-58

Wilson, E. J. (2004). The information revolution and developing countries. Cambridge, MA: MIT Press.

Wilson, E.J. (2012, December). Exclusion and inequality in digital societies: Theories, evidence, and strategy [video file]. Posted by Hutchins Center. Retrieved from https://www.youtube.com/watch?v=EfTw_FbVGLE

Wolf, M., Ullman-Shade, C., \& Gottwald, S. (2012). The emerging, evolving reading brain in a digital culture: Implications for new readers, children with reading difficulties, and children without schools. Journal of Cognitive Education and Psychology, 11(3), 230-240. https://doi.org/10.1891/1945-8959.11.3.230

\section{Copyrights}

Copyright for this article is retained by the author(s), with first publication rights granted to the journal.

This is an open-access article distributed under the terms and conditions of the Creative Commons Attribution license (http://creativecommons.org/licenses/by/4.0/). 